\title{
Aestheic Rehabhilitation through Multidisciplinary Approach -A Case Report
}

\author{
Dr. Aghin Moses ${ }^{1}$, Dr. G. Lambodaran ${ }^{2 *}$, Dr. M. S. Sathyashankar ${ }^{1}$, Dr. H. Annapoorni ${ }^{1}$ \\ ${ }^{1}$ Department of Prosthodontics, Meenakshi Ammal Dental College, Maduravoyal, Alapakkam Main Rd, Janaki Nagar, Maduravoyal, Chennai, Tamil \\ Nadu 600095, India \\ ${ }^{2}$ MDS, Associate Professor, Department of Prosthodontics, Meenakshi Ammal Dental College, Maduravoyal, Alapakkam Main Rd, Janaki Nagar, \\ Maduravoyal, Chennai, Tamil Nadu 600095, India
}

DOI: $10.36348 /$ sjodr.2020.v05i07.011

| Received: 05.07.2020 | Accepted: 24.07.2020 | Published: 28.07.2020

*Corresponding author: Dr. G. Lambodaran

\section{Abstract}

The restoration of lost smile is one of the gratifying things a dentist can render to the society and it plays a significant role in achieving confidence. Just as there are no two smiles alike, there are no two smile makeovers alike. Each smile makeover plan contains a precise combination of treatments designed to address the unique needs and goals of the individual patient. An experienced, skilled dentist will be able to identify the precise approach to be adapted pertaining to the clinical situation which will yield the most stunning results possible. In some cases, that may mean performing just a couple of treatments to produce subtle refinements to a smile. In others, a more comprehensive approach may be necessary. It all depends on the patient needs and the clinical situation. This case report enlightens about an aesthetic rehabhilitation through an interdisciplinary approach.

Keywords: Smile make over, Aesthetic Rehabhilitation, Alveolar Prognathism, Deans Alveoloplasty.

Copyright @ 2020: This is an open-access article distributed under the terms of the Creative Commons Attribution license which permits unrestricted use, distribution, and reproduction in any medium for non-commercial use (NonCommercial, or CC-BY-NC) provided the original author and source are credited.

\section{INTRODUCTION}

In modern day dental practice aesthetics has become an integral part in dentistry as people are being more concerned of their appearance in today's world. Patients with Malaligned teeth seek dental treatment because of its significant impact on function, aesthetics and psychological condition and we come across increased number of young adults who desire cost effective, non- surgical correction of these malocclusions in shortest possible time in our day-today practice. The optimal treatment for these malocclusions may include orthodontic therapy, orthognathic surgery, periodontics and fixed or removable prostheses. If the patients do not accept or undergo optimal dental treatment, other treatment modalities are to be considered. This article describes an aesthetic rehabilitation of severe proclined anterior teeth with a multidisciplinary treatment plan tailored to the patient's needs.

\section{CASE REPORT}

A 36-year-old female patient reported to the Department of Prosthodontics with the chief complaint of forwardly placed upper front teeth, spacing in both upper and lower front tooth and unpleasant smile.
Patient had no significant medical conditions. On clinical examination (Fig-1) the patient had proclined upper and lower anteriors with overjet of $10 \mathrm{~mm}$ and overbite of $5 \mathrm{~mm}$ with no signs of tissue inflammation. The upper and lower incisors exhibited grade II mobility. The upper and lower anterior teeth had gingival recession which can be grouped under millers class III gingival recession. The gingiva around remaining teeth bleed easily on probing and pockets were present in relation to maxillary and mandibular posterior teeth. Radiographic evaluation showed generalized bone loss with maxillary and mandibular teeth. Clinical diagnosis was generalized chronic periodontitis with class II malocclusion. After examining the patient's existing clinical condition and radiographic evaluation, following treatment treatment plan was suggested.

\section{Treatment Plan}

- Periodontal regenerative therapy - Periodontal therapy including scaling, root planing and flap surgery was done and teeth with poor prognosis were advised extraction.

- Extraction of Teeth with poor prognosis 
- Alveoloplasty: Alveoloplasty was suggested to reduce the alveolar proganthism which played a significant role in the unaesthetic smile.

- Root canal treatment for abutment teeth

- Fabrication of Metal ceramic fixed Dental Prosthesis

\section{Treatment Objectives and Procedures}

The treatment goals were to control the periodontal inflammation, stabilize the dentition, correcting proclined teeth and spacing with FDP, ultimately enhancing the patient's Aesthetic appearance which was challenging in the present case as the patient had alveolar prognathism.

Periodontal treatments including oral prophylaxis and subgingival curettage were performed on both arches, followed by flap surgery for posterior teeth. After the periodontal condition was stabilized, after about 2 months (oral prophylaxis and curettage for 4 weeks; flap surgery for 4 weeks), the patient was referred to prosthodontics for rehabhilitation procedure.

\section{Diagnostic Model}

Diagnostic impression (Fig-2) was made using irreversible hydrocolloid impression material for fabrication of study models (Fig-3) facilitating prosthodontic treatment planning. Mock surgery (Fig-4) was done in the dental stone model where all the teeth which are to be extracted were knocked out and the model was trimmed on the labial aspect for reducing the amount of proclination caused by the alveolar bone and to attain the desired arch form. A surgical stent (Fig-5) was fabricated for the upper arch using clear acrylic to function as verification stent to simulate the mock preparation in the patient's mouth. The fabrication of immediate dentures was planned for the upper and the lower anterior region in the mock up model.

\section{Surgical Stent}

Stent guided alveoloplasty was done in the upper anterior region once the extraction was completed. Deans alveoloplasty (Fig-6) was done where the interdental bone was removed in the central and the lateral incisor regions on both sides with a vertical releasing cut made on the bone $3 \mathrm{~mm}$ anterior to the adjacent healthy teeth. Once the cut is made the bone was compressed on the labial aspect and the verified using the surgical stent and the flap was sutured using 3-0 silk suture material.

Once the teeth with unfavourable prognosis were extracted and alveoloplasty was done, the immediate dentures were placed with soft liner. Patient was instructed not to remove the denture for the first 24 hours and followed by that regular cleaning and maintanance of the dentures after first 24 hours.

\section{Intentional Root canal for Abutment Teeth}

The extraction site was allowed to heal and in the mean time intentional root canal treatment was planned and executed for the upper and lower right and left canines to facilitate adequate reduction to achieve optimal esthetics.

\section{Fabrication of Fixed Dental Prosthesis}

Teeth preparation (Fig-7) was done to fabricate metal ceramic fixed dental prosthesis from upper right canine to the upper left canine and also from lower right canine to the lower left canine in the lower arch. Impression was made with poly vinyl siloxane elastomeric impression material. Cementation of definitive prosthesis (Fig-8) was done in the final visit using Glass ionomer cement. Post operative instructions were given. A one year follow up was done with no appreciable changes at the treatment site and the patient was fully satisfied with the improved aesthetic outcome (Fig-9).
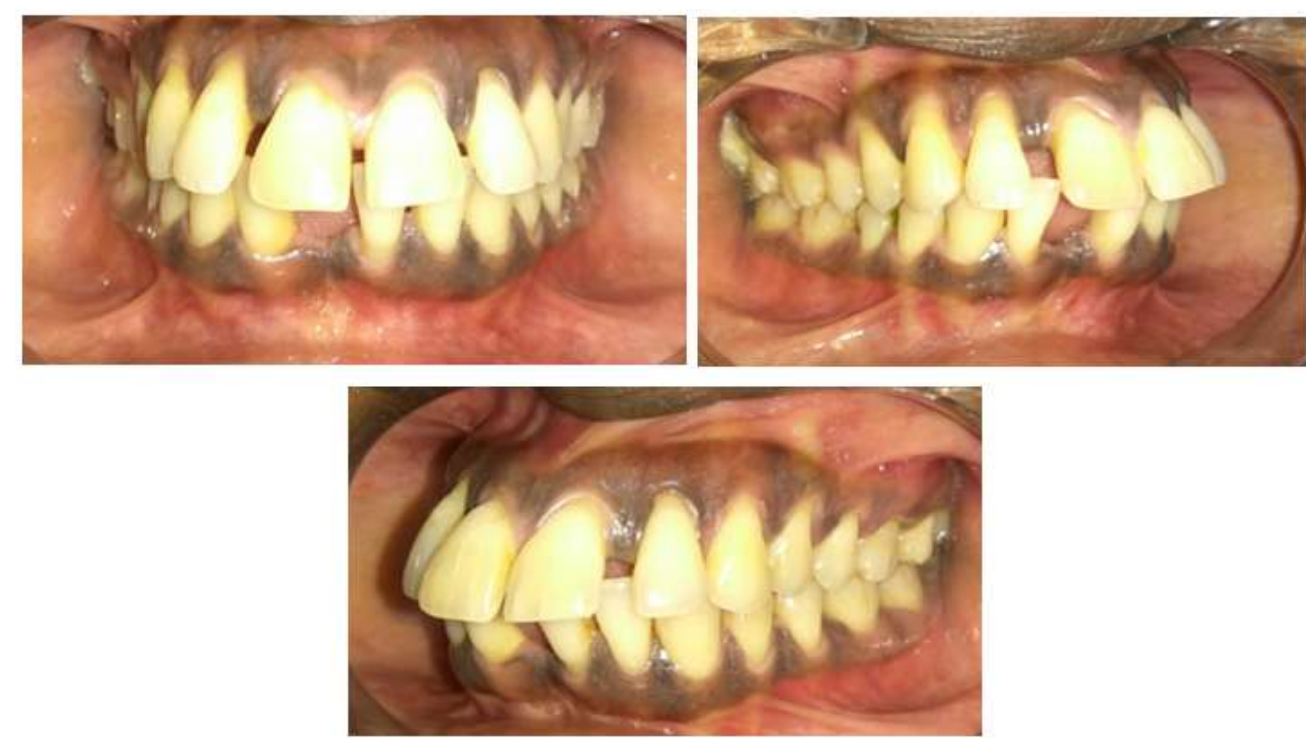

Fig-1: Pre Operative 
Aghin Moses et al; Saudi J Oral Dent Res, July, 2020; 5(7): 358-362
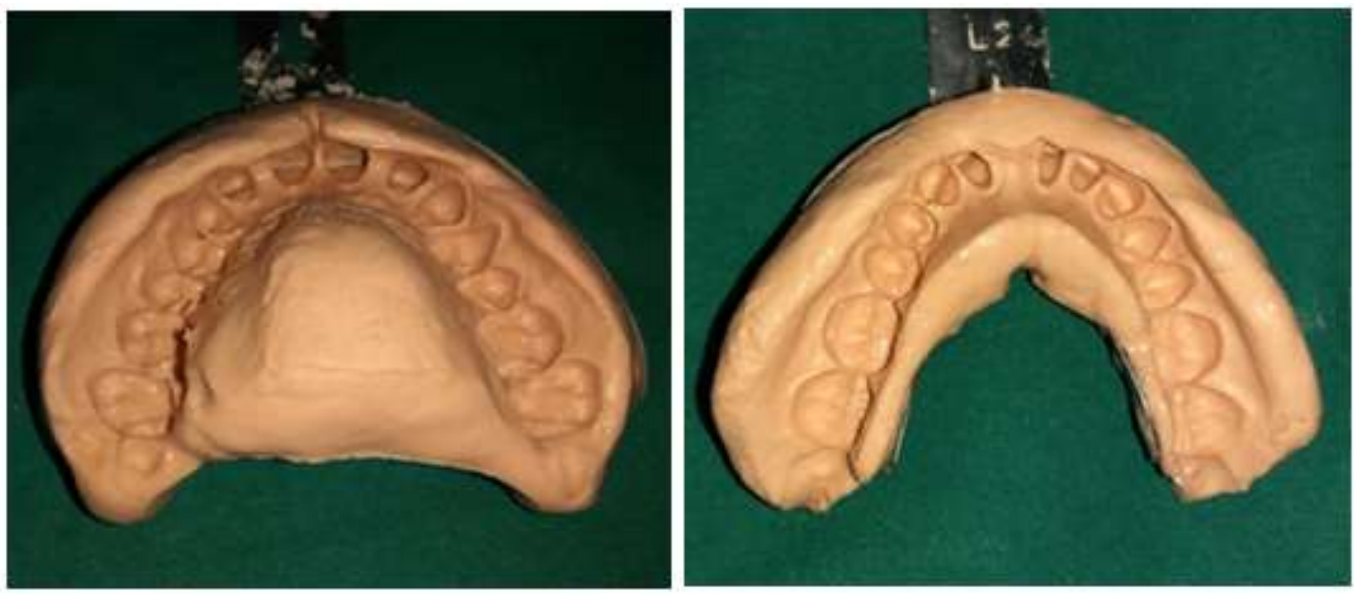

Fig-2: Diagnostic Impression

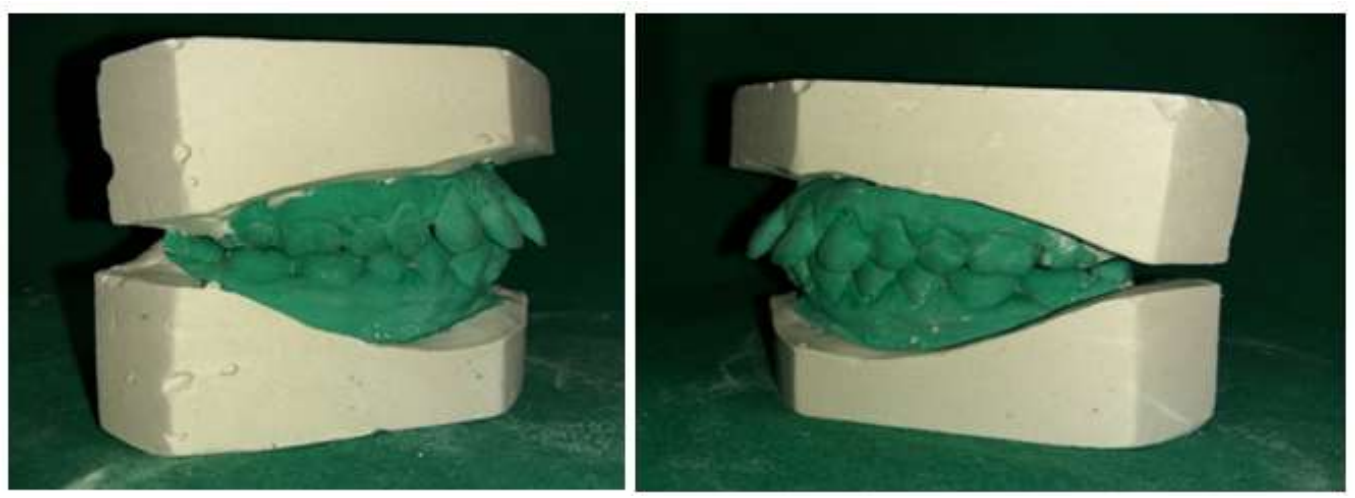

Fig-3: Diagnostic Models

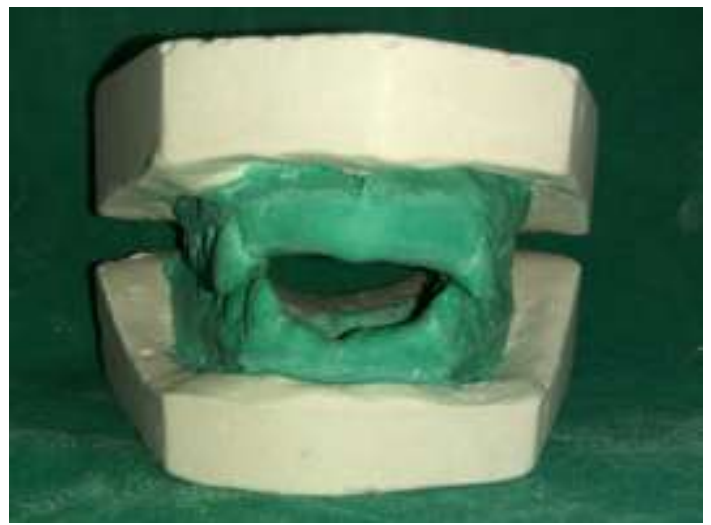

Fig-4: Mock surgery

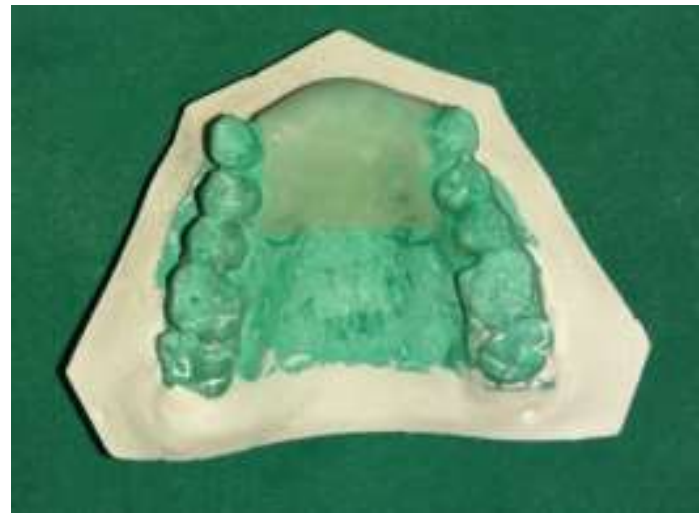

Fig-5: Surgical stent 

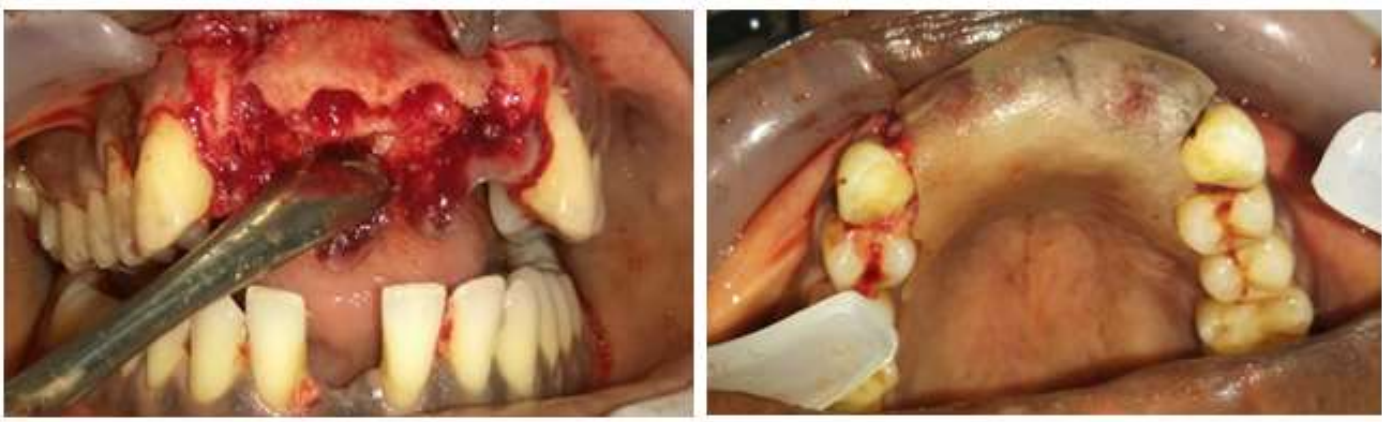

Fig-6: Deans Alveoloplasty and Verification Stent
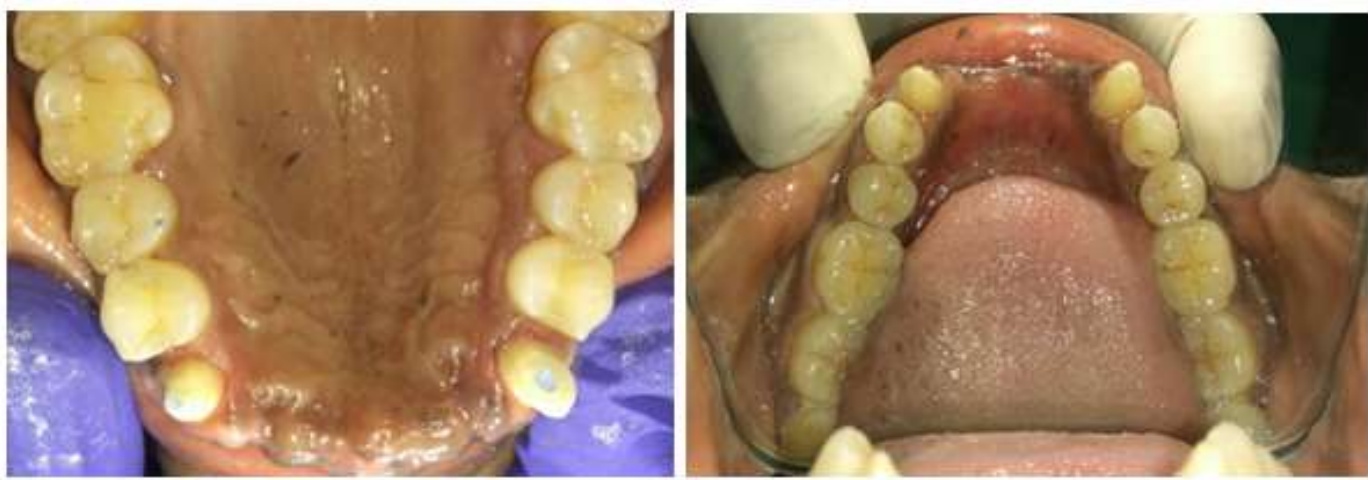

Fig-7: Teeth Preparation

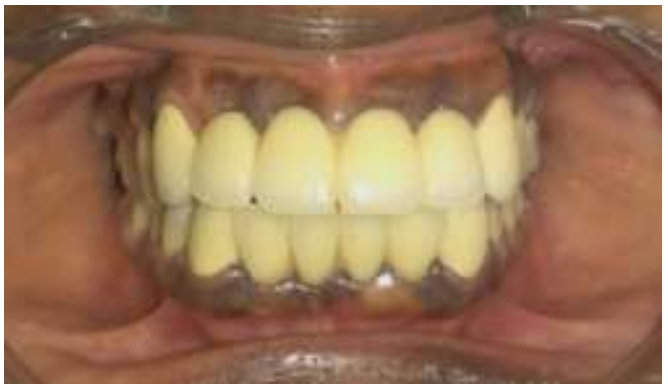

Fig-8: Final prosthesis
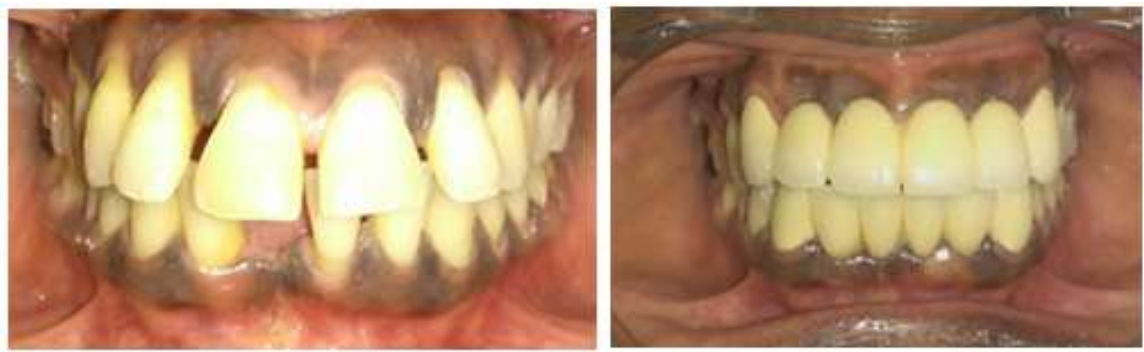

Fig-9: New Smile Makeover

\section{DISCUSSION}

In modern day dental practice aesthetics plays a significant role, making it imperative for a clinician to adopt Aesthetics in his/her practice, joining hands with other specialists to optimize the treatment outcome. The desire for a more aesthetic smile has become one of the most powerful incentives for a visit to the dentist and malocclusion is one such condition that affects aesthetics [1]. Correction of proclined teeth through prosthodontics without involving orthodontics is one such difficult restorative challenge faced in clinical practice [2]. Restorative results can be disastrous if pitfalls are not recognized and addressed in the treatment plan.

In the present case, as there was inadequate bone support, bone grafting had to be preceded by orthodontics and a healing period of 4-6 months was required after regenerative periodontal therapy before initiating an orthodontic therapy [3]. Here the age factor of the patient was also not ideal for orthodontic therapy. Since the anterior maxilla exhibhited alveolar 
prognathism, placement of implants and subsequent prosthesis would also not yield desired aesthetic results. In this scenario, FDP was the most viable option through which aesthetic improvement can be achieved.

For this, a proper diagnostic model is essential to analyse the amount of bone reduction in the anterior maxilla for the reducing the amount of proclination caused by the alveolar bone and to attain the desired arch form and surgical stent provided the best visual guide for the clinician [4]. Following this, the diagnostic wax-up made for interim restoraration following extraction of incisors and alveoplasty of around $2 \mathrm{~mm}$, showed a definitive improvement.

Dean's intraseptal alveoloplasty was carried out following extraction of incisors. It is a technique usually done in maxillary anterior region immediately after extraction to reduce gross maxillary overjet [5, 6]. After extracting incisors, interseptal bone was cutfollowed by vertical cuts in the labial cortex at distal end of the extraction sockets bilaterally. Next, labial cortex was fractured and compressed in approximation with palatal plate and then sharp margins were removed and sutures placed. Immediate removable partial denture was placed during healing period and intentional root canal was performed to facilitate tooth reduction to enhance esthetics.

In the present case, we had opted for metal ceramic restorations considering the cost factor and also the advantages like superior strength, high fracture toughness, high resistance to crack propagation, biocompatibility, durability etc [7-9], making it one of the ideal material of choice for this clinical scenario providing optimal esthetics and function.

\section{CONCLUSION}

This clinical case report enlightens about a successful aesthetic anterior rehabilitation of a patient with dentoalveolar proganthism, in which multidisciplinary treatment planning improved smile aesthetics, resulting in enhanced patient comfort and satisfaction through prosthetic and minimally invasive surgical procedures. This modality of treatment can be opted to improve aesthetics in patients with dentoalveolar and skeletal defects who do not wish to undergo time consuming orthodontic therapy and complex surgical procedure.

\section{REFERENCES}

1. McNamara, L., McNamara Jr, J. A., Ackerman, M. B., \& Baccetti, T. (2008). Hard-and soft-tissue contributions to the esthetics of the posed smile in growing patients seeking orthodontic treatment. American Journal of Orthodontics and Dentofacial Orthopedics, 133(4), 491-499.

2. Drago, C. J., \& Caswell, C. W. (1990). Prosthodontic rehabilitation of patients with class II malocclusions. The Journal of Prosthetic Dentistry, 64(4), 435-445.

3. Zachrisson, B. U. (1996, March). Clinical implications of recent orthodonticperiodonticresearch findings. In Seminars in Orthodontics (Vol. 2, No. 1, pp. 4-12). WB Saunders.

4. Gurel, G. (2013). Discovering the artist inside: A three-step approach to predictable Aesthetic smile designs, Part I. Dent Today. 32(5):74-78

5. Dean, O. T. (1936). Surgery for the denture patient. Journal Am Dent Assoc. 23:21-24.

6. Steinhäuser, E. W. (1976). Dean's alveolotomy for the correction of maxillary protrusion with periodontal disease. Deutsche zahnarztliche Zeitschrift, 31(3), 232-234.

7. Reitemeier, B., Hänsel, K., Kastner, C., Weber, A., \& Walter, M. H. (2013). A prospective 10-year study of metal ceramic single crowns and fixed dental prosthesis retainers in private practice set tings. The Journal of prosthetic dentistry, 109(3), 149-155.

8. Vigolo, P., \& Mutinelli, S. (2012). Evaluation of zirconium- oxide- based ceramic single- unit posterior fixed dental prostheses (FDPs) generated with two CAD/CAM systems compared to porcelain- fused- to- metal single- unit posterior FDPs: a 5- year clinical prospective study. Journal of Prosthodontics: Implant, Esthetic and Reconstructive Dentistry, 21(4), 265269.

9. Rinke, S., Schäfer, S., Lange, K., Gersdorff, N., \& Roediger, M. (2013). Practice- based clinical evaluation of metal-ceramic and zirconia molar crowns: 3- year results. Journal of oral rehabilitation, 40(3), 228-237. 